\title{
Etlik piliçlerde embriyonun erken ve geç gelişim dönemlerinde yapılan yüksek ısıl uygulamanın bazı karkas ve yenilebilir iç organ özelliklerine etkileri
}

\section{Effect of high thermal manipulation during early and late embryogenesis on characteristics of some carcass and edible internal organ traits in broilers}

\author{
Sezai ALKAN ${ }^{1}$, Özgür Barış BİRGÜL ${ }^{2}$ \\ ${ }^{1}$ Ordu Üniversitesi, Ziraat Fakültesi, Zootekni Bölümü, Cumhuriyet Yerleșkesi, ORDU \\ ${ }^{2}$ Akdeniz Üniversitesi, Ziraat Fakültesi, Zootekni Bölümü, ANTALYA
}

Sorumlu yazar (Corresponding author): S. Alkan, e-posta (e-mail): sezaialkan61@gmail.com

MAKALE BILLGISİ

Alınıs tarihi 24 Nisan 2017

Düzeltilme tarihi 08 Eylül 2017

Kabul tarihi 12 Eylül 2017

\section{Anahtar Kelimeler:}

Etlik piliç

Is1l uygulama

Yenilebilir iç organ özellikleri

\begin{abstract}
ÖZ
Bu çalıșmada etlik piliçlerde kuluçka gelișiminin erken ve geç embriyonik dönemlerinde yapılan yüksek 1sıl uygulamanın bazı karkas ve yenilebilir iç organ özelliklerine olan etkilerin belirlenmesi amaçlanmıştır. Bu amaçla kontrol grubu yumurtalarına optimum kuluçka koşulları $\left(37.5^{\circ} \mathrm{C}\right.$ sıcaklık ve $\% 55$ nem) 19 . güne kadar olan gelișim dönemi boyunca uygulanmıştır. Kuluçkanın erken (8-10. günler) ve geç embriyonik (16-18. günler) dönemlerinde ise yumurtalara günlük 3 saat süreyle $(12.00-15.00), 41{ }^{\circ} \mathrm{C}$ sicaklık ve $\% 65$ nem uygulanmıştır. Kontrol, erken ve geç embriyonik dönem gruplarındaki etlik piliçlerin kesim ağırlık ortalamaları sırasıyla $1616.00 ; 1725.83$ ve $1791.13 \mathrm{~g}$ olarak bulunmuş olup gruplar arasında önemli farklılık saptanmıștır $(\mathrm{P}<0.05)$. Denemede kontrol, erken ve gec embriyonik dönem gruplarındaki piliçlerin karkas ağırlık ortalamaları sırasıyla 1180.87; 1276.80 ve $1319.04 \mathrm{~g}$ olarak bulunmuș olup gruplar arasında önemli farkl1l1klar belirlenmiștir $(\mathrm{P}<0.05)$. Toplam yenilebilir iç organ ağırlıkları bakımından deneme grupları arasında bir farklılık bulunmazken, erkek piliçlere ait ortalamalar dişilerden daha yüksek bulunmuştur $(\mathrm{P}<0.01)$.
\end{abstract}

\section{ARTICLE INFO}

Received 24 April 2017

Received in revised form 08 September 2017

Accepted 12 September 2017

Keywords:

Broiler

Thermal manipulation

Edible internal organ traits

\begin{abstract}
The aim of this study was to determine the effect of thermal manipulations during early and late embryogenesis on some carcass and edible internal organ traits in broiler chickens. Incubation conditions were $37.5^{\circ} \mathrm{C}$ and $55 \%$ relative humidity for control group throughout the incubation period until the $19^{\text {th }}$ day. In the thermally treated eggs during early embryogenesis, incubation temperature was increased to $41{ }^{\circ} \mathrm{C}$ and relative humidity to $65 \%$ for 3 hours $(12.00-15.00)$ on the $8^{\text {th }}-10^{\text {th }}$ days of incubation. Also, in the late embryogenesis stage incubation temperature was increased to $41{ }^{\circ} \mathrm{C}$ and relative humidity to $65 \%$ for 3 hours (12.00-15.00) on the $16^{\text {th }}-18^{\text {th }}$ days of incubation. Slaughter weight of broilers in control, early and late embryonic groups were determined as $1616.00 ; 1725.83$ and $1791.13 \mathrm{~g}$, respectively and, significant difference was found among the groups in terms of slaughter weight $(\mathrm{P}<0.05)$. Also, average carcass weights of broilers in control, early and late embryonic groups were found to be as $1180.87 ; 1276.80$ and $1319.04 \mathrm{~g}$, respectively. Differences among the groups were determined significant. While there was no significant difference in point of total edible internal organs among the groups, values of the males were found to be higher than the females $(\mathrm{P}<0.01)$.
\end{abstract}

\section{Giriş}

Üstün genotipik yapıdaki piliçlerin uygun olmayan çevre koşullarında barındırılmaları fizyolojik sorunları da beraberinde getirmektedir. Örneğin, yüksek sıcaklık ve nem kanatlı endüstrisi için büyük bir sorun teşkil etmektedir. Günümüzde uluslararası damızlık şirketlerinin çoğu serin iklim kuşağındaki ülkelerde yer almaktadır. Buna karşın, dünya kanatlı eti ve yumurta üretiminin büyük bir kısmı sıcak iklim kuşağında bulunan ülkelerde gerçekleştirilmektedir. Serin iklim bölgelerinde uygun koşullar altında geliştirilen yüksek verimli etlik piliç hibritleri çevrenin bazı olumsuz etkilerine (sıcaklık ve nem) karşı dayanıklılık yeteneklerini kaybetmiş, uygulanan yoğun ıslah programları hibritlerin yüksek sıcaklık nem 
koşullarında 1S1 stresi sorunlarıyla karşılaşmasına yol açmıştır (Yahav ve ark. 2004).

Stres, vücudun belirli mekanizma ve sistemlerinde denge ve uyum bozukluğu sonucunda meydana gelen tepkisel davranışlar ve biyokimyasal değişiklikler şeklinde ifade edilmektedir. Strese maruz kalan kanatlı hayvanların vücutlarında başlangıçta hızlı ve geçici, sonra ise kalıcı ve geri dönüşü olmayan bazı olumsuz değişimler gerçekleşmektedir. Stres sonucunda da verim kayıpları ve hastalıklara karşı direncin azalması kaçınılmazdır.

Son yıllarda 1sı stresinin kanatlı yetiştiriciliğindeki olumsuz etkilerini azaltmak için epigenetik çalışmalardan faydalanılmaktadır. Kanatlıların isı stresine karşı koyma yetenekleri, vücut sicaklığını dengeleme sistemleri henüz etkinleşmeden, erken yaşlarda isıl şok uygulamasıyla geliştirilebilmektedir (Yahav 2000). Isı stresine alıştırma (aklimasyon) organizmanın yaşam süresi içinde meydana gelen ve canlının çevrenin sıcaklık ve nemine karşı zorlanmasını azaltan ya da direncini artıran fizyolojik ya da davranışsal değişikliklerdir. Isı stresine alıştırma sırasında 1sı üretimi ve 1s1 yayımı için vücudun sıcaklık eşiği değişmekte, bu nedenle kanatlının 1s1 stresine tolerans1 yükselmektedir (Tzschentke ve ark. 2001; Nichelmann 2004).

$\mathrm{Bu}$ 1sıl uygulama çalışmaları temel olarak kuluçka ve kuluçka sonrası dönemlerde yapılmasına göre ikiye ayrılmaktadır. Kuluçka öncesi dönem, vücut sıcaklığını dengeleme sistemleri açısından oldukça önemli bir dönemdir. Kuluçka süresince yapılan yüksek sicaklık ve nem uygulamalarının temeli epigenetik adaptasyonun da temeli olup kuluçka boyunca edilen fizyolojik hafizanın hayat boyu kullanılmasını ifade etmektedir. Kuluçka sırasında yapılacak olan 1s1l uygulamalarda 3 ölçüt göz önünde bulundurulmaktadır. Bunlardan birincisi, 1sıl uygulama embriyo gelişiminin hangi aşamasında yapılacak; ikincisi hangi sıcaklık ve nem değerleri kullanılacak ve üçüncüsü ise seçilen sıcaklık ve nem değerleri ne kadar süre ile uygulanacaktır.

Hızlı gelişme ve et verimi yönünde sağlanan genetik ilerlemeler sonucunda etlik piliçlerde giderek kısalan kesim yaş1, embriyo dönemindeki gelişme düzeyinin ve civciv kalitesinin daha fazla önem kazanmasına yol açmıştır. Kuluçka süresi olan 21 gün günümüz koşullarında etlik piliçlerin yaşam ömrünün yarısına tekabül etmektedir. Bu nedenle kuluçka döneminde embriyo gelişimini destekleyecek ya da sınırlayacak her türlü etkenin etlik piliçlerin performansını ve sağlığını etkileyeceği bilinmektedir (De Oliveira ve ark. 2008). Bu düşüncelerin dayanağ ve kanatlı hayvanlarda kuluçka koşullarının değişimi sonucunda organizmada fizyolojik kontrol sistemlerinde ortaya çıkan ve yaşam boyu etkisini sürdüren değişikliklerdir (Decuypere ve Bruggeman 2007). Etlik piliçlerde 1S1 zorlanımına karşı alınabilecek başlıca önlemler dört başlık altında toplanmaktadır. Bunlar; yapısal çevrede yapılabilecek düzenlemeler, beslemeyle ilgili alınabilecek önlemler, 1s1 zorlanımına dayanıklı genotiplerin geliştirilmesi ve epigenetik çalışmalar (sıcaklık ve nem uygulanması) olup son zamanlarda epigenetik çalışmalar üzerinde yoğun olarak durulmaktadır.

$\mathrm{Bu}$ çalışmada da kuluçkanın erken ve geç gelişim dönemlerinde yapılan yüksek 1sıl uygulamaların etlik piliçlerde yenilebilir iç organ özelliklerine olan etkilerinin belirlenmesi amaçlanmıştır.

\section{Materyal ve Yöntem}

Araştırma, Akdeniz Üniversitesi Ziraat Fakültesi Zootekni Bölümü Hayvancılık Tesisleri'nde yürütülmüştür. Araştırmanın materyalini Ross 308 genotipine ait toplam 600 adet yumurta, bu yumurtalardan elde edilen civcivler ile civciv ve piliçlerin beslenmesinde $0-3$ haftalar arasinda $\% 23$ ham proteinli ve $2850 \mathrm{kkal} \mathrm{kg}^{-1}$ metabolik enerjili, 4-6 haftalar arasında ise \% 21 ham proteinli ve $3000 \mathrm{kkal} \mathrm{kg}^{-1}$ metabolik enerjili yemler kullanılmış olup su serbest olarak verilmiştir.

Kuluçka aşamasında her bir grubu oluşturan yumurtalar ayrı gelişim makinesinde kuluçkalandırılmıştır. Kuluçkalık yumurtalar kuluçka makinesine konulmadan önce numaralandırılmış ve $0.01 \mathrm{~g}$ hassasiyetteki elektronik terazi ile tartılmıştır. Yumurtaların rastgele 200 tanesine kuluçka süresinin erken embriyonik gelişim döneminde (8-10. günler arasında) ve 200 tanesine de geç embriyonik gelişim döneminde (16-18. günler arasında) 3 saat süreyle (12.00-15.00 saatleri arasında) $41{ }^{\circ} \mathrm{C}$ sicaklık ve $\% 65$ nem uygulanmıştır. Kontrol grubunu oluşturan 200 adet yumurta ise kuluçka süresince standart sıcaklık $\left(37.5^{\circ} \mathrm{C}\right)$ ve nem $(\%$ 55) koşullarına maruz bırakılmıştır. Kuluçkada çevirme ve havalandırma işlemleri otomatik olarak yapılmıştır. Her üç gruba ait yumurtalar kuluçka süresinin son üç gününde $37.2{ }^{\circ} \mathrm{C}$ sıcaklık ve $\% 75$ nem ortamı sağlanan çıkış bölümüne aktarılmıştır. Deneme süresince ortamın sıcaklık ve nemi data logger ile sürekli olarak kaydedilmiş olup bu sıcaklık ve nem değerleri kullanılarak haftalık ortalama sicaklık ve nem değerleri hesaplanmıştır. Bu değerlerden yararlanılarak ta haftalık toplam 1sı değerleri aşağıdaki eşitliğe göre hesaplanmıştır (Alkan ve Mutaf 2008).

$$
\begin{aligned}
& Q_{\text {toplam }}: C p * t_{k}+\left(595+0.46 * t_{k}\right) * m_{\ddot{o} n} \\
& \mathrm{~T}_{\text {oplam }}: \text { Toplam 1s1 }\left(\mathrm{kkal} \mathrm{kg}^{-1} \text { kuru hava }\right)
\end{aligned}
$$$$
\text { Cp: Havanın kütlesel özgül ısısı }\left(0.24 \mathrm{kkal} \mathrm{kg}^{-1}{ }^{\circ} \mathrm{C}^{-1}\right)
$$$$
\mathrm{t}_{\mathrm{k}} \text { : Havanın kuru termometre sıcaklığ } 1\left({ }^{\circ} \mathrm{C}\right)
$$

595: Suyun sıfir $\left(0^{\circ} \mathrm{C}\right)$ derecedeki buharlaşma 1sısı

$$
\text { (kkal kg-1 kuru hava) }
$$

0.46: Su buharının özgül 1sısı $\left(\mathrm{kkal} \mathrm{kg}^{-1}{ }^{\circ} \mathrm{C}^{-1}\right)$

$\mathrm{m}_{\text {ön }}$ : Özgül nem ( $\mathrm{kg} \mathrm{H}_{2} \mathrm{O} \mathrm{kg}^{-1}$ kuru hava).

Çıkışı yapılan civcivlerden 360 adeti pencereli tavuk kümesinde, etlik piliçlerin üretimine uygun bölmelere nakledilmiş olup her uygulama grubunda 120 adet civciv kullanılmıştır. Etlik piliçler her biri $1.95 \times 1.5 \mathrm{~m}$ boyutlarında olan toplam 12 adet yer bölmesine yetiştirilmiştir. Deneme 3 muamele ve 4 tekerrürlü olarak tesadüf parselleri deneme desenine göre düzenlenmiş ve yaz mevsiminde Temmuz ve Ağustos aylarında 6 hafta sürmüştür.

Karkas özelliklerinin belirlenebilmesi için denemenin sonunda her bir gruptan rastgele 10 erkek-10 dişi etlik piliç seçilmiştir. Kesimden yaklaşık 10 saat önce yemler kaldırılmıştır. Kesim işlemi yapıldıktan sonra $58{ }^{\circ} \mathrm{C}$ sıcaklıkta 60 saniye bekletilerek islak yolma yapılarak karkas, baş, ayak, kalp, taşlık ve karaciğer ağıllıkları ve oranları yüzde olarak saptanmıştır (Melnychuk ve ark. 1997).

Elde edilen verilerin analizlerinde SAS (1998) paket programı kullanılmıştır. 


\section{Bulgular ve Tartışma}

\subsection{Sicaklık, nem ve toplam ısı değerleri}

Deneme ortamının ortalama sicaklık, nem ve toplam 1s1 değerleri Çizelge 1' de verilmiştir. En yüksek sıcaklık ortalamas 1 5. haftada $\left(32.46 \pm 0.28{ }^{\circ} \mathrm{C}\right)$ olmasına rağmen, nem değeri ortalamasının diğer haftalara nazaran daha düşük (\% 42.73 \pm 3.48$)$ seyretmesinden dolay1 toplam 1s1 değeri (15.72 kkal) düşük bulunmuştur. Bu da sicaklığın tek başına etken olamayacağını aynı zamanda nem değerlerinin de 1sıyı hesaplamada ne kadar etkin olduğunu göstermektedir.

Çizelge 1. Sıcaklık $\left({ }^{\circ} \mathrm{C}\right)$, nem (\%) ve toplam 1 sı $\left(\mathrm{kkal} \mathrm{kg}^{-1}\right)$ değerleri.

Table 1. Temperature $\left({ }^{\circ} \mathrm{C}\right)$, humidity $(\%)$ and total heat values $\left(\mathrm{kcal} \mathrm{kg}^{-1}\right)$.

\begin{tabular}{|c|c|c|c|c|c|}
\hline Hafta & Sicaklık $\pm \mathrm{SH}^{1}$ & Minimum & Maksimum & $\mathrm{Nem} \pm \mathrm{SH}^{1}$ & Toplam 1s1 \\
\hline 1 & $30.54 \pm 0.17$ & 25.27 & 36.62 & $65.90 \pm 3.53$ & 18.29 \\
\hline 2 & $30.93 \pm 0.18$ & 26.31 & 34.85 & $73.11 \pm 4.31$ & 19.60 \\
\hline 3 & $30.22 \pm 0.18$ & 25.23 & 34.53 & $74.82 \pm 3.52$ & 19.73 \\
\hline 4 & $31.74 \pm 0.22$ & 26.75 & 38.04 & $70.85 \pm 4.52$ & 20.24 \\
\hline 5 & $32.46 \pm 0.28$ & 25.54 & 40.28 & $42.73 \pm 3.48$ & 15.72 \\
\hline 6 & $29.79 \pm 0.27$ & 22.44 & 38.31 & $56.78 \pm 4.56$ & 15.98 \\
\hline
\end{tabular}

\subsection{Etlik piliçlerin kesim, karkas, kafa ve ayak ă̆ırlıkları}

Araştırmada kontrol, erken ve geç embriyonik dönem gruplarına ait erkek ve dişi piliçlerin kesim ağırlığı, karkas ağırlığı, karkas randımanı, kafa ve ayak ağırlıkları ile oranlarına ait değerler Çizelge 2'de verilmiştir. Söz konusu çizelgeden de görülebileceği üzere, kontrol, erken ve geç embriyonik dönem gruplarındaki etlik piliçlerin kesim ağırlığı ortalamaları sırasıyla
$1616.00 ; 1725.83$ ve 1791.13 g olarak bulunmuş olup erken ve geç embriyonik dönem grupları ile kontrol grubu arasında önemli farklılık saptanmıştır $(\mathrm{P}<0.05)$. Erkek piliçlerin kesim ağırlığı (1843.53 g) dişi piliçlerden (1578.44 g) daha yüksek bulunmuştur $(\mathrm{P}<0.01)$.

Kuluçkanın 18-21. günleri arasında 2 saat ve 24 saat süreyle yüksek sıcaklık ve nem uygulaması yapan Tzschentke ve Halle (2009) 1s1l uygulamanın sadece erkek etlik piliçlerin kesim ağırlıkları üzerinde etkisinin olduğunu ve dişiler bakımından ısıl uygulama grupları arasında bir farklılık olmadığını saptamışlardır. En yükssek kesim ağırlığının (2336 g) günlük 2 saatlik yüksek sıcaklık uygulanan piliçlerde olduğunu belirlemişlerdir. Tzschentke ve Halle (2009) tarafindan bildirilen kesim ağırlıkları araştırma sonuçlarımızdan yüksek bulunurken en yüksek kesim ağırlıkları benzer şekilde geç embriyonik dönemde yüksek sicaklık uygulanan grupta saptanmıştır. Kuluçkanın 10-18. günleri arasında günlük 6 saat süreyle $39.6{ }^{\circ} \mathrm{C}$ sıcaklık uygulaması yapan Yalçın ve ark. (2010) kuluçkadan çıktıktan sonra civcivleri bir günlük yaştayken iki gruba ayırarak yarısına yüksek sıcaklık uygulamışlardır. Araştırmada en yüksek kesim ağırlığı hem kuluçkada hem de 1 günlük yaşta yüksek sıcaklık uygulaması yapılan piliçlerde elde edilmiştir. Araştırıcılar çalışma bulgularımızla uyumlu olarak 1sıl uygulamanın kesim ağırlığını arttırdığını vurgulamışlardır.

Kuluçka döneminin erken, geç ve hem erken hem de geç embriyonik dönemlerinde 1sıl uygulama yapan Collin ve ark. (2007) araştırma bulgularımızın aksine grupların 43 günlük yaştaki kesim ağırlıkları arasında herhangi bir farklılık olmadığını belirlemişlerdir. Aynı araştırmada kontrol, erken, geç ve erken-geç embriyonik dönem gruplarındaki piliçlerin kesim ağırlıkları sırasıyla 2591; 2620; 2617 ve 2616 g olarak bulunmuştur. Hulet ve ark. (2007) embriyonik gelişimin geç dönemlerinde yüksek sıcaklık uygulamış, gruplarda 44 günlük yaşa ait kesim ağırlıklarının 2095.1-2176.6 g arasında olduğunu ve gruplar arasında bir farklılık olmadığını bildirmişlerdir.

Çizelge 2. Etlik piliçlerin kesim, karkas, kafa, ayak ağırlıkları ve oranları.

Table 2. Slaughter, carcass, head and foot weights and ratio of broilers.

\begin{tabular}{|c|c|c|c|c|c|c|c|c|}
\hline \multicolumn{2}{|c|}{ Muamele } & $\begin{array}{c}\text { Kesim } \\
\text { A ğırlığ }(\mathrm{g}) \\
\end{array}$ & $\begin{array}{c}\text { Karkas } \\
\text { A ğırlığ } 1(\mathrm{~g}) \\
\end{array}$ & $\begin{array}{c}\text { Karkas } \\
\text { Randımanı (\%) } \\
\end{array}$ & $\begin{array}{c}\text { Kafa } \\
\text { A ğgrlığ }(\mathrm{g}) \\
\end{array}$ & $\begin{array}{c}\text { Kafa } \\
\text { Oranı }(\%) \\
\end{array}$ & $\begin{array}{c}\text { Ayak } \\
\text { Ağgrlığ }{ }_{1}(\mathrm{~g}) \\
\end{array}$ & $\begin{array}{c}\text { Ayak } \\
\text { Oranı (\%) } \\
\end{array}$ \\
\hline \multicolumn{2}{|l|}{ Kontrol } & $1616.00 \pm 35.29^{\mathrm{b}}$ & $1180.87 \pm 29.51^{\mathrm{c}}$ & $72.14 \pm 0.47^{\mathrm{b}}$ & $49.76 \pm 0.73$ & $3.10 \pm 0.06$ & $70.81 \pm 1.53$ & $4.38 \pm 0.08^{\mathrm{a}}$ \\
\hline \multicolumn{2}{|l|}{$\mathrm{EED}^{1}$} & $1725.83 \pm 35.29^{\mathrm{a}}$ & $1276.80 \pm 29.51^{\mathrm{b}}$ & $73.88 \pm 0.47^{\mathrm{a}}$ & $51.78 \pm 0.73$ & $3.04 \pm 0.06$ & $67.30 \pm 1.53$ & $3.90 \pm 0.08^{\mathrm{b}}$ \\
\hline \multicolumn{2}{|l|}{$\mathrm{GED}^{2}$} & $1791.13 \pm 35.29^{a}$ & $1319.04 \pm 29.51^{\mathrm{a}}$ & $73.70 \pm 0.47^{\mathrm{a}}$ & $51.07 \pm 0.73$ & $2.86 \pm 0.06$ & $72.18 \pm 1.53$ & $4.02 \pm 0.08^{\mathrm{b}}$ \\
\hline \multicolumn{9}{|l|}{ Cinsiyet } \\
\hline \multicolumn{2}{|l|}{ Erkek } & $1843.53 \pm 28.81^{\mathrm{a}}$ & $1361.68 \pm 24.10^{\mathrm{a}}$ & $73.35 \pm 0.39$ & $54.29 \pm 0.60^{\mathrm{a}}$ & $2.97 \pm 0.05$ & $80.28 \pm 1.25^{\mathrm{a}}$ & $4.39 \pm 0.07^{\mathrm{a}}$ \\
\hline \multicolumn{2}{|l|}{ Dişi } & $1578.44 \pm 28.81^{\mathrm{b}}$ & $1156.13 \pm 24.10^{\mathrm{b}}$ & $73.13 \pm 0.39$ & $47.46 \pm 0.60^{\mathrm{b}}$ & $3.03 \pm 0.05$ & $59.92 \pm 1.25^{\mathrm{b}}$ & $3.81 \pm 0.07^{\mathrm{b}}$ \\
\hline \multicolumn{9}{|c|}{ Mua*Cinsiyet } \\
\hline \multirow{2}{*}{ Kontrol } & Erkek & $1784.75 \pm 49.90^{\mathrm{b}}$ & $1327.35 \pm 41.74^{\mathrm{b}}$ & $72.93 \pm 0.67^{b}$ & $54.21 \pm 1.03$ & $3.07 \pm 0.09$ & $81.71 \pm 2.17$ & $4.63 \pm 0.11^{\mathrm{a}}$ \\
\hline & Dişi & $1447.25 \pm 49.90^{\mathrm{d}}$ & $1034.40 \pm 41.74^{\mathrm{d}}$ & $71.35 \pm 0.67^{\mathrm{c}}$ & $45.30 \pm 1.03$ & $3.14 \pm 0.09$ & $59.92 \pm 2.17$ & $4.13 \pm 0.11^{\mathrm{b}}$ \\
\hline \multirow{2}{*}{ EED } & Erkek & $1841.50 \pm 49.90^{\mathrm{a}}$ & $1352.05 \pm 41.74^{\mathrm{b}}$ & $73.28 \pm 0.67^{b}$ & $54.75 \pm 1.03$ & $3.01 \pm 0.09$ & $78.71 \pm 2.17$ & $4.31 \pm 0.11^{\mathrm{b}}$ \\
\hline & Dişi & $1610.17 \pm 49.90^{\mathrm{c}}$ & $1201.54 \pm 41.74^{\mathrm{c}}$ & $74.48 \pm 0.67^{\mathrm{a}}$ & $48.82 \pm 1.03$ & $3.06 \pm 0.09$ & $55.89 \pm 2.17$ & $3.50 \pm 0.11^{\mathrm{d}}$ \\
\hline \multirow{2}{*}{ GED } & Erkek & $1904.33 \pm 49.90^{\mathrm{a}}$ & $1405.64 \pm 41.74^{\mathrm{a}}$ & $73.84 \pm 0.67^{\mathrm{b}}$ & $53.91 \pm 1.03$ & $2.84 \pm 0.09$ & $80.41 \pm 2.17$ & $4.22 \pm 0.11^{\mathrm{b}}$ \\
\hline & Dişi & $1677.92 \pm 49.90^{\mathrm{c}}$ & $1232.43 \pm 41.74^{\mathrm{c}}$ & $73.56 \pm 0.67^{\mathrm{b}}$ & $48.24 \pm 1.03$ & $2.88 \pm 0.09$ & $63.95 \pm 2.17$ & $3.81 \pm 0.11^{\mathrm{c}}$ \\
\hline \multicolumn{4}{|c|}{ Varyasyon Kaynakları } & Önem Düzeyi & & & & \\
\hline \multicolumn{2}{|c|}{ Muamele } & $0.003 *$ & $0.005^{*}$ & $0.021^{*}$ & 0.146 & 0.088 & 0.075 & $0.000 *$ \\
\hline \multicolumn{2}{|c|}{ Cinsiyet } & $0.000^{*}$ & $0.000^{*}$ & 0.691 & $0.000 *$ & 0.431 & $0.000 *$ & $0.000 *$ \\
\hline \multicolumn{2}{|c|}{ Muamele*Cinsiyet } & $0.008^{*}$ & $0.014^{*}$ & $0.033^{*}$ & 0.515 & 0.986 & 0.427 & $0.018^{*}$ \\
\hline
\end{tabular}

${ }^{1}$ Erken embriyonik dönem, ${ }^{2} \mathrm{Geç}$ embriyonik dönem, ${ }^{\text {a.b.c.d }}$ aynı sütunda farklı harflerle gösterilen ortalamalar arasındaki farklar önemlidir $(\mathrm{P}<0.01 ; 0.05)$. 
Denemede kontrol, erken ve geç embriyonik dönem gruplarındaki piliçlerin karkas ağırlık ortalamaları sırasıyla $1180.87 ; 1276.80$ ve 1319.04 g olarak bulunmuş olup gruplar arasında önemli farklılıklar saptanmıştır $(\mathrm{P}<0.05)$. Erkek piliçlerin karkas ağırlığı (1361.68 g).dişilerden (1156.13 g) daha yüksek bulunmuştur $(\mathrm{P}<0.05)$. En yüksek karkas ağırlığı geç embriyonik dönem grubunun erkeklerinde (1405.64 g) saptanırken, en düşük ise kontrol grubunun dişilerinde $(1034.40 \mathrm{~g})$ belirlenmiştir $(\mathrm{P}<0.05)$. Benzer şekilde karkas randımanları bakımından da kontrol, erken ve geç embriyonik dönem grupları arasında önemli farklılıklar gözlenmiş $(\mathrm{P}<0.05)$ olup erken ve geç embriyonik dönem gruplarındaki piliçlerinin karkas randımanının kontrol grubundan daha yüksek olduğu belirlenmiştir. Dişi ve erkek piliçlerin karkas randımanları arasındaki farklılık önemsiz bulunmuştur.

Geç embriyonik dönemde yüksek sıcaklık uygulaması gerçekleştiren Molenaar ve ark. (2011) 42 günlük yaşta kesilen etlik piliçlerin karkas ağırlıklarının yüksek sıcaklık grubunda 2166, kontrol grubunda ise $2188 \mathrm{~g}$ olduğunu ve gruplar arasında önemli farklılık olmadığını bildirmişlerdir. Bunun aksine Hulet ve ark. (2007) farklı yüksek sıcaklık uygulanmış grupların 44 günlük yaşa ait kesim ağırlıklarının 2165.7-2263.3 $\mathrm{g}$ arasında değiştiğini ve gruplar arasında önemli farklılık bulunduğunu ve bulgularımızla uyumlu olacak şekilde 16-18. günler arasında $38.6{ }^{\circ} \mathrm{C}$ yüksek sıcak uygulanan piliçlerin kesim ağırlıklarının daha yüksek olduğunu bildirmişlerdir. Her iki araştırmada saptanan karkas ağırlıkları araştırmamızda saptanan değerlerden daha yüksek bulunmuştur. Hulet ve ark. (2007) tarafindan yapılan çalışmada gruplar için saptanan karkas randımanlarının \% 74.88-73.61 arasında değiștiği ve gruplar arasında herhangi bir farklılık olmadığı bildirilmiştir.

Kuluçkanın 18. gününden çıkışa kadar günlük 24 saat ve 2 saat süreyle yüksek sicaklık uygulayan Halle ve Tzschentke (2011) kontrol grubuyla isil uygulama yapılan gruplardaki etlik piliçlerin karkas randımanları arasında önemli farklılıklar olduğunu ve en yüksek karkas randımanının (\% 74.4) sürekli yüksek sıcaklık uygulanan grupta saptandığını bildirmiş̧lerdir.
Söz konusu çalışmada karkas randımanları \% 71.0-74.2 arasında saptanmış olup araştırmamızın sonuçlarıyla uyumlu bulunmuştur. Günal (2013) tarafından gerçekleştirilen bir araştırmada ise piliçlere 5 günlük yaşta yüksek sıcaklık uygulaması yapılmış ve 6 haftalık yaşta kesilen piliçlerin karkas randımanlarının kontrol ve deneme gruplarında sirasiyla $\% 70.91$ ve $\% 71.28$ olarak bulunmuştur. Araştırma sonuçlarımıza benzer olarak Günal (2013) 1sıl uygulamanın karkas randımanını arttırdığını bildirmiştir. Benzer bir çalışmada yetiştirme döneminde yüksek sıcaklık uygulamasının 42 günlük yaşta kesilen etlik piliçlerin karkas randımanında artışa neden olduğu bildirilmiştir (Erköse ve Akşit 2009).

Çizelge 2'de görüldüğü gibi, araştırmada kafa ağırlığı ve oranı bakımından kontrol, erken ve geç embriyonik dönem grupları arasında önemli bir farklılık bulunmamıştır. Bunun yanında erkek piliçlerin kafa ağırlığ $(54.29 \mathrm{~g})$ dişilerinkinden $(47.46 \mathrm{~g})$ daha yüksek saptanmıştır $(\mathrm{P}<0.05)$. Fakat kafa oranları bakımından cinsiyetler arasında önemli bir farklılık bulunmamıştır $(\mathrm{P}>0.05)$.

Denemede ayak ağırlıkları bakımından da kontrol, erken ve geç embriyonik grupları arasında önemli bir farklılık bulunmamıştır $(\mathrm{P}>0.05)$. Cinsiyetler bakımından ayak ağırlıkları arasında önemli farklılık bulunmuş olup erkeklerin ayak ağırlığ 1 (80.28 g) dişilerinkinden (59.92 g) daha yüksek bulunmuştur $(\mathrm{P}<0.05)$. En yüksek ayak oranı ortalaması $(\% 4.63)$ kontrol grubundaki erkek piliçlerde saptanırken, en düşük ise erken embriyonik dönem grubundaki dişi piliçlerde (\% 3.50) gözlenmiştir $(\mathrm{P}<0.05)$.

\subsection{Etlik piliçlerin yenilebilir iç organ ağırlıkları}

Araştırmada kontrol, erken ve geç embriyonik dönem gruplarına ait erkek ve dişi piliçlerin kalp, karaciğer, taşlık ve toplam yenilebilir iç organ ağırlıklarına ilişkin ortalamalar ve söz konusu organ ağırlıklarının karkas ağırlığındaki oranları Çizelge 3'de sunulmuştur. Çizelge 3'den de görülebileceği

Çizelge 3. Etlik piliçlerin yenilebilir iç organ ağırlıkları ve oranları.

Table 3. Edible internal organ weights and ratio of broilers.

\begin{tabular}{|c|c|c|c|c|c|c|c|c|c|}
\hline \multirow{2}{*}{\multicolumn{2}{|c|}{ Muamele }} & \multicolumn{2}{|c|}{ Kalp } & \multicolumn{2}{|c|}{ Karaciğer } & \multicolumn{2}{|c|}{ Taşlık } & \multicolumn{2}{|c|}{ Toplam Yenilebilir İç Organ } \\
\hline & & Ağırlık (g) & Oran $(\%)$ & Ağırlık (g) & Oran $(\%)$ & Ağırlık (g) & Oran $(\%)$ & Ağırlık (g) & Oran $(\%)$ \\
\hline Kontrol & & $9.70 \pm 0.55$ & $0.60 \pm 0.03$ & $29.88 \pm 0.96$ & $1.85 \pm 0.05$ & $30.37 \pm 1.13$ & $1.88 \pm 0.06$ & $69.95 \pm 1.92$ & $4.33 \pm 0.09$ \\
\hline $\mathrm{EED}^{1}$ & & $9.20 \pm 0.52$ & $0.53 \pm 0.03$ & $29.00 \pm 0.92$ & $1.68 \pm 0.05$ & $30.21 \pm 1.08$ & $1.75 \pm 0.06$ & $68.41 \pm 1.83$ & $3.97 \pm 0.08$ \\
\hline $\mathrm{GED}^{2}$ & & $10.16 \pm 0.52$ & $0.56 \pm 0.03$ & $31.92 \pm 0.92$ & $1.78 \pm 0.05$ & $32.56 \pm 1.08$ & $1.82 \pm 0.06$ & $74.64 \pm 1.83$ & $4.17 \pm 0.08$ \\
\hline \multicolumn{10}{|l|}{ Cinsiyet } \\
\hline Erkek & & $10.61 \pm 00.44^{\mathrm{a}}$ & $0.57 \pm 0.02$ & $32.61 \pm 0.77^{\mathrm{a}}$ & $1.76 \pm 0.04$ & $33.27 \pm 0.91^{\mathrm{a}}$ & $1.80 \pm 0.05$ & $76.50 \pm 1.54^{\mathrm{a}}$ & $4.14 \pm 0.07$ \\
\hline Dişi & & $8.76 \pm 00.43^{b}$ & $0.56 \pm 0.02$ & $27.93 \pm 0.75^{\mathrm{b}}$ & $1.78 \pm 0.04$ & $28.82 \pm 0.88^{b}$ & $1.83 \pm 0.05$ & $65.50 \pm 1.49^{\mathrm{b}}$ & $4.17 \pm 0.07$ \\
\hline \multicolumn{10}{|c|}{ Mua*Cinsiyet } \\
\hline \multirow{2}{*}{ Kontrol } & Erkek & $10.62 \pm 00.81$ & $0.59 \pm 0.04$ & $31.91 \pm 1.42$ & $1.77 \pm 0.07$ & $32.45 \pm 1.68$ & $1.81 \pm 0.09$ & $74.98 \pm 2.84$ & $4.16 \pm 0.13$ \\
\hline & Dişi & $8.79 \pm 00.74$ & $0.61 \pm 0.04$ & $27.85 \pm 1.30$ & $1.93 \pm 0.07$ & $28.29 \pm 1.53$ & $1.95 \pm 0.08$ & $64.92 \pm 2.59$ & $4.50 \pm 0.12$ \\
\hline \multirow{2}{*}{ EED } & Erkek & $10.35 \pm 00.74$ & $0.56 \pm 0.04$ & $31.76 \pm 1.30$ & $1.73 \pm 0.07$ & $32.78 \pm 1.53$ & $1.78 \pm 0.08$ & $74.88 \pm 2.59$ & $4.07 \pm 0.12$ \\
\hline & Dişi & $8.05 \pm 00.74$ & $0.50 \pm 0.04$ & $26.25 \pm 1.30$ & $1.64 \pm 0.07$ & $27.64 \pm 1.53$ & $1.73 \pm 0.08$ & $61.94 \pm 2.59$ & $3.87 \pm 0.12$ \\
\hline \multirow{2}{*}{ GED } & Erkek & $10.88 \pm 00.74$ & $0.57 \pm 0.04$ & $34.16 \pm 1.30$ & $1.79 \pm 0.07$ & $34.60 \pm 1.53$ & $1.82 \pm 0.08$ & $79.63 \pm 2.59$ & $4.18 \pm 0.12$ \\
\hline & Dişi & $9.43 \pm 00.74$ & $0.56 \pm 0.04$ & $29.68 \pm 1.30$ & $1.78 \pm 0.07$ & $30.53 \pm 1.53$ & $1.81 \pm 0.08$ & $69.64 \pm 2.59$ & $4.15 \pm 0.12$ \\
\hline \multicolumn{3}{|c|}{ Varyasyon Kaynakları } & Önem Dü & & & & & & \\
\hline \multicolumn{2}{|c|}{ Muamele } & 0.438 & 0.284 & 0.079 & 0.055 & 0.240 & 0.280 & 0.051 & 0.055 \\
\hline \multicolumn{2}{|c|}{ Cinsiyet } & $0.004^{*}$ & 0.668 & $0.000^{*}$ & 0.698 & $0.001 *$ & 0.659 & $0.000^{*}$ & 0.714 \\
\hline \multicolumn{2}{|c|}{ Muamele*Cinsiyet } & 0.847 & 0.554 & 0.853 & 0.193 & 0.929 & 0.437 & 0.812 & 0.087 \\
\hline
\end{tabular}

${ }^{1}$ Erken embriyonik dönem, ${ }^{2}$ Geç embriyonik dönem, ${ }^{\text {a.b }}$ aynı sütunda farklı harflerle gösterilen ortalamalar arasındaki farklar önemlidir $(\mathrm{P}<0.01 ; 0.05)$. 
üzere, erkek piliçlerin yürek, karaciğer ve taşlık ağırlık ortalamaları, dişi piliçlerin ortalamalarından daha yüksek bulunmuştur $(\mathrm{P}<0.05)$. Toplam yenilebilir iç organ ağırlıkları bakımından deneme grupları arasında bir farklılık bulunmazken $(\mathrm{P}>0.05)$, erkek piliçlere ait ortalamalar dişilerden daha yüksek bulunmuştur $(\mathrm{P}<0.01)$.

Kuluçkanın 19. ve 20. günlerinde $40^{\circ} \mathrm{C}$ yüksek sıcaklık uygulayan Leksrisompong ve ark. (2007) söz konusu uygulamanın yürek oranını azalttığını, karaciğer oranında artışa yol açtığını ve taşlık oranına ise herhangi bir etkisi olmadığını ileri sürmüşlerdir. Postnatal dönemde yüksek sıcaklık uygulayan Yalçın ve ark. (2001) sıcaklık uygulanan grup ile ve kontrol grubundaki piliçlerin yürek oranlarının 35 günlük yaşta $\% 0.47$ ve $\% 0.48,49$ günlük yaşta ise $\% 0.40$ ve $\% 0.42$ olduğunu bildirmişlerdir. Araştırıcılar çalışma sonuçlarımızla uyumlu olarak 1sıl uygulamanın yürek oranları üzerinde etkisi olmadığını bildirmişlerdir. Farklı görüş bildiren Günal (2013) 1sıl uygulamanın 42 günlük yaşta kesilen etlik piliçlerde yürek oranı üzerinde artışa neden olduğunu ileri sürmüştür. Çalışma sonuçlarımızla uyumlu olarak. Tzschentke ve Halle (2009) ile Halle ve Tzschentke (2011) geç embriyonik dönemde yapılan yüksek sıcaklık uygulamasının yürek, taşlık ve karaciğer oranları üzerinde herhangi bir etkisinin bulunmadığını bildirmişlerdir.

\section{Sonuç}

Kanatlı hayvanların verim dönemlerinde 1S1 stresine karşı koyabilme yetenekleri henüz vücut sıcaklığını dengeleme sistemleri gelişmeden kuluçka aşamasında yapılan 1sıl uygulamalarla geliştirilebilir. Kuluçka aşamasında yapılan yüksek 1sıl uygulamalarla 1sı stresine alıştırma ile 1sı üretimi ve 1S1 yayımı için vücudun sıcaklık eşiği değişmekte ve buna bağlı olarak da kanatlı hayvanların 1S1 stresine karşı toleransları yükselmektedir. Kuluçkanın erken ve geç gelişim dönemlerinde yapılan yüksek 1sıl uygulamaya maruz bırakılan etlik piliçlerin kesim ve karkas ağırlıkları kontrol grubundakilerden önemli derecede daha yüksek olduğu belirlenmiştir. Buna karşın yenilebilir organlar bakımından deneme grupları arasında önemli bir farklılık bulunmamıştır. Kuluçka aşamasında yapılan 1sıl uygulamanın kesim ağırlı̆̆ını ve 1sı stresine karşı koymayı olumlu yönde etkilediği söylenebilir.

\section{Teşekkür}

Maddi katkılarından dolayı Akdeniz Üniversitesi Bilimsel Araştırma Projeleri Yönetim Birim'ine teşekkür ederiz (proje no: 2010.03.0121.005).

\section{Kaynaklar}

Alkan S, Mutaf S (2008) Farklı sıcaklık ve nem koşullarının farklı genotiplerdeki etlik piliçlerin vücut sıcaklıklarına ve canlı ağırlıklarına etkileri. Akdeniz Üniversitesi Ziraat Fakültesi Dergisi 21(1): 45-54.

Collin A, Berri C, Tesseraud S, Rodon FE, Skiba-Cassy S, Crochet S, Duclos MJ, Rideau N, Tona K, Buyse J, Bruggeman V, Decuypere E, Picard M, Yahav S (2007) Effects of thermal manipulation during early and late embryogenesis on thermo tolerance and breast muscle characteristics in broiler chickens. Poultry Science 86: 795-800.

Decuypere E, Bruggeman V (2007) The endocrine interface of environmental and egg factors affecting chick quality. Poultry Science 86: 1037-1042.
De Oliveira JE, Uni Z, Ferket PR (2008) Important metabolic path ways in poultry embryos prior to hatch. World's Poultry Science Journal 64: 488-499.

Erköse M, Akşit M (2009) Etlik piliçlerin yüksek çevre sıcaklığına alıştırılması. Hayvansal Üretim 50(1): 38-44.

Günal M (2013) The effects of early-age thermal manipulation and daily short-term fasting on performance and body temperatures in broiler exposed to heat stress. Journal of Animal Physiology and Animal Nutrition 97(5), 854-860.

Halle I, Tzschentke B (2011) Influence of temperature manipulation during the last 4 days of incubation on hatching results, posthatching performance and adaptability to warm growing conditions in broiler chickens. Poultry Science 48: 97-105.

Hulet R, Gladys D, Hill D, Meijerhof R, El-Shiekh T (2007) Influence of egg shell embryonic incubation temperature and broiler breeder flock age on posthatch growth performance and carcass characteristics. Poultry Science 86: 408-412.

Leksrisompong N, Romero-Sanchez H, Plumstead PW, Brannan KE, Brake J (2007) Broiler incubation. 1. Effect of elevated temperature during late incubation on body weight and organs of chicks. Poultry Science, 86: 2685-2691.

Melnychuk VL, Robinson FE, Renema RT, Hardin RT, Emmerson DA, Bagley LG (1997) Carcass traits and reproductive development at the onset of lay in two lines of female turkeys. Poultry Science 76: 1197-1204.

Molenaar R, Hulet R, Meijerhof R, Maatjens CM, Kemp B, Van Den Brand H (2011) High eggshell temperatures during incubation decrease growth performance and increase the incidence of ascites in broilerchickens. Poultry Science 90: 624-632.

Nichelmann M (2004) Perinatal epigenetic temperature adaptation in avian species: comparison of turkey and muscovy duck. Journal of Thermal Biology 29: 613-619.

SAS (1998) SAS-STAT Software. Version 6.12. SAS Institute Inc Cary, N.C.

Tzschentke B, Basta D, Nichelmann M (2001) Epigenetic temperature adaptation in birds: peculiarities and similarities in comparison to acclimation. Nervus Biomedical Science 1: 26-31.

Tzschentke B, Halle I (2009) Influence of temperature stimulation during the last 4 days of incubation on secondary sex ratio and later performance in male and female broiler chicks. British Poultry Science 50: 634-640.

Yahav S (2000) Domestic fowl-strategies to confront environmental conditions. Avian Poultry Biology Reviews, 11: 81-95.

Yahav S, Collin A, Shinder D, Picard M (2004) Thermal manipulations during broiler chick embryogenesis: Effects of timing and temperature. Poultry Science 83: 1959-1963.

Yalçın S, Özkan S, Türkmut L, Siegel PB (2001) Responses to heat stress in commercial and local broiler stocks. 1. Performance traits. British Poultry Science 42: 149-152.

Yalçın S, Babacanoğlu E, Güler HC, Akşit M (2010) Effects of incubation temperature on hatching and carcass performance of broilers. World's Poultry Science Journal 66: 87-93. 